\title{
First Heart Sound
}

\author{
Amar Narayan Patnaik ${ }^{1}$ \\ ${ }^{1}$ Cardiologist, Star Hospitals, Banjara Hills, Hyderabad, Telangana, \\ India
}

Ind J Car Dis Wom 2019;4:107-109

\section{Introduction}

The heart sounds (S1, S2, S3, and S4) are discrete short auditory events caused due to vibrations that are generated during the closure of the valve leaflets or tensing of the chorda tendineae. ${ }^{1}$ They are distinct from murmurs that are longer and are caused by turbulent blood flow. They are identified by the timing in the cardiac cycle, location, intensity, pitch, and quality. The first heart sound is conventionally referred to as S1 and has multiple high-frequency components. But only the first two sets (temporally related to the closure of mitral and tricuspid valves) are identified as two componentsthe mitral (M1) and tricuspid (T2); M1 always precedes T1. These two components are not easily appreciated separately in health as the separation interval is $<30 \mathrm{~ms}$. Being a highpitched sound, it is best heard with the diaphragm, which may have to be applied with sufficient pressure to listen to the S1. The quality is described as booming, duller, and longer than S2. The variations in the first sound such as split, intensity, and quality can suggest the underlying pathology to some extent. Mitral component is best heard at the apex and is louder than the tricuspid component due to the higher pressures in the left side of the heart; it can be widely heard in other areas of auscultation as well. ${ }^{2,3}$

\section{Genesis of S1}

The first heart sound is generated at the end of diastole when the atrioventricular (AV) valves reach their greatest excursion, and the blood volume is suddenly halted. A stretch recoil and subsequent vibrations in the cardio-hemic system, including tensing of chordae tendineae, results in the audible first heart sound. The $\mathrm{S} 1$ precedes the upstroke of carotid pulsation. ${ }^{4}$

\section{Auscultation of S1}

High pitched sounds (S1 and S2) are best heard with the stethoscope. An experienced observer can realize the time relation of S1 and S2 and the rhythmic pairing to identify the S1 and S2 (-Table 1). An examination is best conducted in a warm and quiet room.
Address for correspondence Amar Narayan Patnaik, MD, DM, FSCAI, FACC, Senior Consultant Cardiologist, Star Hospitals, 8-2-594/B, Rd Number 10, Banjara Hills, Hyderabad, Telangana 500034, India (e-mail: anpatnaik@yahoo.com).

- Explain to the patient what is going to be done.

- Ensure supine position with adequate exposure of the area to be examined.

- Ensure your stethoscope has recommended features for good auscultation.

- Keep your hands and stethoscope clean and warm.

- Better complete inspection and palpation of the whole precordium first.

- It is common practice to begin the auscultation at aortic area; inching to pulmonary, tricuspid and mitral areas.

- At times turning to the left or bending forward with breath held at maximum expiration make it more obvious.

- Try to concentrate on one sound at a time. Listen to several cycles before concluding about intensity and quality of any sound.

- First heart sound is best heard with the diaphragm.

- A look at apex for the impulse (or the movement of a stethoscope with each beat) or the upstroke of carotid have additional clues to identify the S1. One may place a finger on carotid for accurate timing.

- Analysis of any acoustic event has to be coordinated with the venous, arterial, and chest wall pulsations.

Table 1 Tricks to identify S1

\begin{tabular}{|l|}
\hline Timing \\
\hline Just before carotid upstroke \\
\hline S1 initiates the outward LV thrust of apex \\
\hline Characteristics \\
\hline Medium frequency sound \\
\hline Lower pitch than S2 \\
\hline Loud M1 may mask T1 \\
\hline Longer than S2 \\
\hline Best heard in mitral area \\
Split best in tricuspid area \\
\hline Q-M1 $=60$ ms \\
Q-T1 $=90$ ms \\
M1-T1 $=30$ ms \\
\hline
\end{tabular}

Abbreviation: LV, left ventricle.

(C)2019 Women in Cardiology and Related Sciences
License terms

$($ () (1) $\Theta \circledast$ 


\section{Normal heart sounds}

\$1

s2

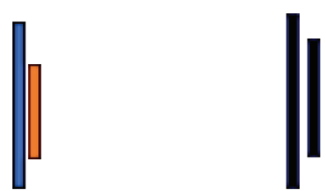

Split first heart sound/RBBBB

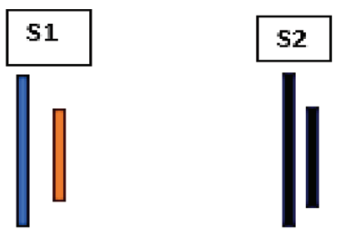

LBBB Leads to merging of M1 and T1

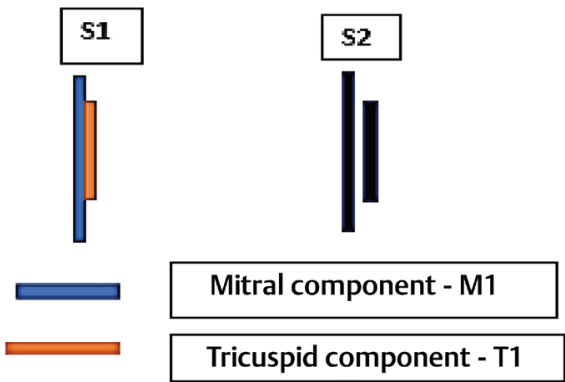

Fig. 1 Relationship between M1 and T1 in normal, RBBB, and LBBB conduction.

\section{Split S1}

As M1 precedes TI, a split may be heard more so in tricuspid area, especially in deepinspiration, which can increase venous return to right heart and delay the tricuspid valve closure. Common causes of abnormal split first heart sound include right bundle branch block (RBBB), atrial septal defect (ASD), premature ventricular contraction (PVCs) (left ventricle [LV] origin), LV pacing, Ebstein's anomaly, or ventricular tachycardia. ${ }^{5}$ In RBBB, the LV is stimulated earlier, and it contracts faster, and M1 occurs earlier. Left bundle branch block (LBBB) has an opposite effect with no split of S1 heard ( $\mathbf{- F i g .} \mathbf{1}$ ). Reverse S1 is a theoretical possibility when M1 can follow T1 in conditions such as LBBB, right ventricle pacing, severe mitral stenosis (MS), and left atrial myxoma; but it is very difficult to appreciate on clinical grounds.

\section{Differential Diagnosis of Split S1}

Three important confusing situations are possible with a split S1- (1) S4-S1, (2) S1-ejection sound, and (3) S1 and early ejection click (of mitral valve prolapse syndrome [MVPS]). S4 is a low-pitched late diastolic sound. It is best heard with the bell of stethoscope when lightly pressed; on further pressure of the bell, it may be attenuated. When left sided, it is best heard at apex and is at times palpable. On standing, S4 fades off due to lessened venous return.
Ejection sound is a high-pitched early systolic sound, best heard at the base, a place where a split S1 is not well heard. Many times, it may not be easy to differentiate these two auscultatory events. Ejection click in MVPS is a late systolic event and better heard on standing.

\section{Loud S1 (Loud M1)}

The intensity of first heart sound depends on thickness of chest wall, PR interval, valve leaflet mobility, and ventricular contractility. In thin-chest walled adults and the children may have loud S1, while in the obese, the S1 may not be heard well. The primary factor that decides the loudness is the position of the AV valves at the beginning of ventricle systole. Wider the leaflets are separated, louder is the S1. Longer PR interval allows longer diastolic filling time, and the leaflets come closer with the resultant increase in LV pressure. Such closer separation of leaflets makes the valve closure sound softer. Conversely, a short PR result in a loud S1. The wider leaflets are separated at end-diastole, the more rapid is their closure and louder the S1. Thus, mitral stenosis, VSD, or PDA with significant shunts, tachycardia, and pre-excitation syndromes can have loud S1. In mild-to-moderate noncalcific mitral stenosis, the increased left atrial pressure widely separates the two mitral leaflets, making the myocardial infarction (MI) accentuated. In critical densely calcified MS, the leaflets are immobile diminishing the intensity of M1. A loud S1 generally indicates a pliable valve. In tachycardia, there is a faster rise in ventricular pressure, and it results in a louder S1. Thus, in conditions such as anemia, thyrotoxicosis, or sepsis, S1 can be accentuated. Positive inotropes result in rapid rise in ventricular pressure and a loud S1. See the -Table 1 for various mechanisms of loud $\mathrm{S} 1 .{ }^{4}$ - Table 2 summarizes the mechanisms of loud M1. A loud T1 may be a manifestation of Ebstein's anomaly, ASD, or straight-back syndrome.

\section{Muffled S1}

Prolonged PR interval (bradycardia, 1-degree heart block, digitoxicity) or diminished force of ventricular contractions (cardiomyopathy, myocarditis, myocardial infarction [MI], or myxoedema) or densely calcified MV or post-irradiation states can diminish the loudness of S1. Due to inadequate apposition of mitral leaflets (mitral regurgitation [MR], tricuspid

Table 2 Mechanisms producing loud S1

\begin{tabular}{|l|l|}
\hline Mechanism & Examples \\
\hline Increased transvalvar gradient & MS, TS, LA myxoma \\
\hline $\begin{array}{l}\text { Increased force of ventricular } \\
\text { contraction }\end{array}$ & $\begin{array}{l}\text { Tachycardia, hyperdy- } \\
\text { namic states like anemia, } \\
\text { thyrotoxicosis, exercise, } \\
\text { inotropes }\end{array}$ \\
\hline Shortened PR interval & $\begin{array}{l}\text { Tachycardia, WPW } \\
\text { syndrome }\end{array}$ \\
\hline $\begin{array}{l}\text { Less tissue between heart and } \\
\text { the diaphragm }\end{array}$ & Thin chest wall \\
\hline
\end{tabular}

Abbreviation: LA, left atrial; MS, mitial stenosis; PR, pulmonary regurgitation; TS, tricuspid stenosis; WPW, Wolff-Parkinson-White. 
regurgitation [TR], dilated cardiomyopathy [DCMP]), there can be a muffled S1. Early closure of the mitral valve due to raised left ventricular end-diastolic pressure in acute aortic regurgitation $[A R]$ can make S1 muffled. Conditions such as obesity, pleural effusion, pericardial effusion, bronchial asthma, chronic obstructive pulmonary disease, emphysema, and pneumothorax increase the tissue between heart and stethoscope and the intensity of S1 can decrease significantly in such situations. ${ }^{6}$

\section{Unusual Findings}

Loud S1-Though it is common to expect a soft S1 in the presence of MR, in MVPS it may be surprisingly loud.

Soft S1-In severe MS, the S1 can be soft if there is heavy calcification, associated MR, myocarditis, or cardiac shock.

\section{Variable Intensity of S1}

Mobitz type-1 heart block, electrical alternans, digitalis toxicity, atrial fibrillation, pulsus alternans, and ventricular tachycardia with AV dissociation cause variation in the intensity of first heart sound either due to variable forces of ventricular contractions or change in PR interval. ${ }^{6}$

\section{Conclusion}

Accurate clinical identification of the first heart sound has to be practiced by all medicos and clinicians. The variations in its characteristics have to be interpreted along with other auscultatory events; not in isolation.

\section{Conflict of Interest}

None.

\section{References}

1 Perloff JK. Cardiac auscultation. Dis Mon 1980;26(9):1-47

2 Lakier JB, Fritz VU, Pocock WA, Barlow JB. Mitral components of the first heart sound. Br Heart J 1972;34(2):160-166

3 Lakier JB, Bloom KR, Pocock WA, Barlow JB. Tricuspid component of first heart sound. Br Heart J 1973;35(12):1275-1279

4 Luisada AA, MacCanon DM, Kumar S, Feigen LP. Changing views on the mechanism of the first and second heart sounds. Am Heart J 1974;88(4):503-514

5 Crews TL, Pridie RB, Benham R, Leatham A. Auscultatory and phonocardiographic findings in Ebstein's anomaly. Correlation of first heart sound with ultrasonic records of tricuspid valve movement. Br Heart J 1972;34(7):681-687

6 Higgins JP. Physical examination of the cardiovascular system. Int J Clin Cardiol 2015;2:1 